\title{
IC 10 Frame-based guide to situated decision-making on climate change
}

Climate change adaptation and mitigation requires decision-making that is highly sensitive to the specifics of a situation. It calls for "situated decision-making" that can stand in the service of adequate action. However, guides to decision-making generally ignore the specifics, focusing largely on methods and tools that abstract information out of situations without any reflection on the context.

Situated decision-making is based on strategies that enable a decision-maker to be informed by a rich store of information and, at the same time, ensure a degree of flexibility and adaptability.
The development of a decision-making strategy can be supported using Thompson's two basic dimensions of decision. The first dimension refers to beliefs about the cause/effect relations that are instrumental for what the decision might actually accomplish; the second refers to preferences regarding the possible outcomes of the decision. Accordingly, there can be certainty or uncertainty regarding causation and certainty or uncertainty regarding outcome preferences. Figure 1 presents the patterns of uncertainty of the two dimensions.

Figure 1. The two basic dimensions of decision combined

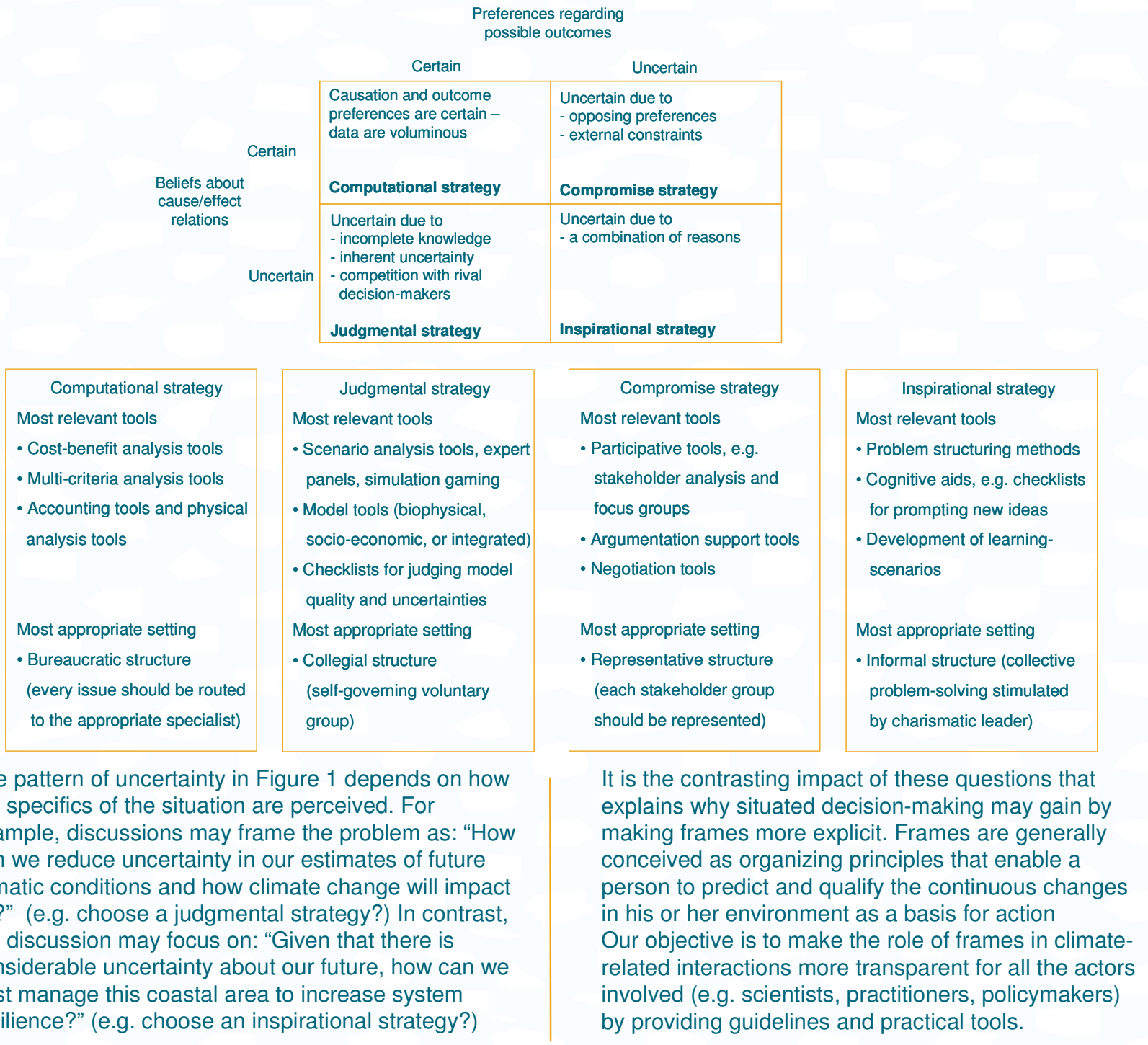

Dr Joop de Boer, Institute for Environmental Studies, Vrije Universiteit Amsterdam.

Dr Jeroen van der Sluijs, Drs. Arjan Wardekker, Copernicus Institute for Sustainable Development and Innovation, Utrecht University. Dr Karen Buchanan. Dr Rien Kolkman, Prof. Dr A van der Veen, Water Engineering \& Management group, University of Twente. 